\title{
HUELLAS DE HEGEL ${ }^{1}$
}

\author{
José M. ${ }^{a}$ RIPALDA \\ (Departamento de Filosofia, UNED)
}

\section{I.}

Se puede decir que a lo largo de los últimos 35 años se ha deshecho una de las leyendas más famosas y, desde Dilthey, pertinaces sobre Hegel. Esa leyenda era la de un joven Hegel romántico y visionario, panteísta y antisistémico, descubierto por el historicismo berlinés contra la fría especulación del profesor avejentado, en la que se habría apoyado el marxismo. Hace tiempo que nos vamos acostumbrando a encontrar en el joven Hegel la tópica de que se alimentó y a descubrir el sentido de muchos pasajes de madurez en los apuntes juveniles.

Una parte decisiva en este giro se debe a los trabajos de la edición crítica, que en estos últimos años se centran precisamente en las clases berlinesas. Lo último publicado, los apuntes de $\mathrm{H}$. Hotho del curso de estética de 1823/1824, ha aportado nuevos matices y confirma que la Enciclopedia de las Ciencias Filosóficas, pese a su apariencia dogmática y petrificada, encierra en sus diferentes versiones $(1817,1827,1830,1840)$ la codificación en forma

1 Reelaboro en este texto una ponencia pronunciada en Salamanca durante el I Congreso de la Sociedad Espanola de Estudios sobre Hegel (5-9 de Mayo de 1998). Agradezco a la profesora M.a Carmen PAREDES el amable permiso para disponer de este texto. Siglas utilizadas:

Fenomenologia. G. W. F. HEGEl, Fenomenologia del Espiritu. Trad. W. ROCES (colaborador R. GUERRA). México: FCE, 1966.

HGW: G. W. F. HEGEL. Gesammelte Werke. Ed. Rheinisch-Westfälische Akademie der Wissenschaften in Verb. mit der Deutschen Forschungsgemeinschaft. Hamburg: Meiner, 1968-. HW: G. W. F. HEGEL. Werke in zwanzig Bänden. Frankfurt: Suhrkamp, 1970-1979. 
escolarizada de un constante rumiar, madurar y ampliar intuiciones que en gran parte fueron juveniles. El resumen que da la Enciclopedia del famoso tema del "fin del arte" indica, pese a su compacidad, el núcleo del pensamiento de Hegel en este punto. Y son temas como éste y el "fin de la historia" los que siguen generando titulares en la cultura contemporánea. Claro que los infinitos "fin del» (arte, del libro, de la historia, del hombre, etc., etc.) corresponden sobre todo a unos segundos años de postguerra, en que la cultura hegemónica trataba de afrontar su propia disolución a base de tematizarla con tonillos retóricos existenciales. Despojados de ese énfasis, que en Hegel no se dio, dan motivo de reflexión en la coyuntura contemporánea.

En este contexto ha sido muy oportuna la publicación en castellano de la Enciclopedia por Ramón Valls Plana (Madrid: Alianza, 1997). Lo que voy a hacer a continuación fundamentalmente es cotejar el texto berlinés con la Filosofia real de 1805/06 (Madrid: FCE, 1984), en el curso de cuya anotación, así como en el Comentario a la Filosofia del Espiritu de Hegel (Madrid: UNED, FCE, 1993), ya había tenido que enfrentarme con ese gran manual de Hegel. Y es que los mismos editores de la Enciclopedia en las primeras Obras de Hegel (1832-45), sobre todo Michelet, consideraron ambos textos tan paralelos que incluyeron en apéndices buena parte de la Filosofia real junto con otros pasajes inéditos. Si Valls no los ha tenido en cuenta, es sin duda porque el volumen resultante, realmente "enciclopédico", habría hecho menos asequible el libro con contrapartidas más bien escasas; como Valls indica, se halla en curso la edición de las clases berlinesas en que se basan muchos de ellos, y mientras tanto procede la precaución en el uso de esos materiales ${ }^{2}$. Por otra parte la intención de ser un compendio ya se hallaba bastante desvirtuada por la misma extensión

2 Por lo demás la edición más usada de las Obras de Hegel, la de Moldenhauer y Michel en Suhrkamp, reproduce los apéndices en espera de que la edición crítica vaya depurando esos materiales. De todos modos, por lo que va apareciendo de las clases en la serie azul, se ve que esta tarea no es acabable. Nunca se podrá equiparar el texto de las clases que, como Hegel mismo quería, recomponfan los alumnos, con el de una obra escrita 'ex professo' o, ni siquiera, con un manuscrito del propio Hegel. Así F. Hespe y B. Tusching en su edición de las clases correspondientes a los parágrafos de la Enciclopedia que van a ser comentados a continuación: G. W. F. HEGEL, Vorlesungen. Ausgewählte Nachschriften und Manuskripte. Bd. 13 (=Vorlesungen über die Philosophie des Geistes. Berlin 1827/1828), págs. 282 s.

Por otra parte los apéndices tienen valor de fuente para explicaciones de Hegel perdidas, y en este caso suelen añadir explicaciones y polémicas coherentes con el corpus escrito, pero que carecían de lugar incluso en las notas de la Enciclopedia. Cuando los use a continuación, lo haré a reserva de su valor textual. Cf. en la introducción de Valls su punto $8 .^{\circ}$. 
que había ido tomando la Enciclopedia de 1817 en sus dos ediciones posteriores, de 1827 y 1830 , cuando su propósito expreso era presentar el sistema en su conjunto y ya disponemos razonablemente de la explanación detallada de sus diversas partes. También nota Valls Plana que la sistemática de los apéndices preberlineses no encaja siempre en el texto tardío. De hecho las discusiones alemanas de los años 70 sobre la teoría hegeliana de la sociedad (así Manfred Riedel, Jürgen Habermas, Gerhard Göhler) se ocuparon intensamente de estos textos de Jena, que habían permanecido inéditos en su conjunto hasta $1931^{3}$. Así como la Enciclopedia constituye el manual del sistema una vez alcanzado, los cursos de Jena son el intento definitivo de llegar a ese sistema, culminado el mismo año en que se estrena la Heroica de Beethoven, con las clases de 1805/06. Esa carga final, obsesiva y sombría, se lanza directamente hacia el núcleo especulativo, perdiendo por el camino parte del enorme bagaje concreto que había sostenido explícitamente hasta entonces la especulación. De ahí lo esencial de las líneas, lo duro y concentrado de la exposición, en realidad imposible como curso escolar. Pues bien, mi comentario de Hegel se va a mover, como digo, precisamente en el hiato entre los textos de $1805 / 1806$ y 1807/1830).

II.

El curso de 1805/06 hace culminar la Filosofia de la naturaleza con el sexo, la enfermedad y la muerte del animal, es decir del cuerpo. A partir de esa fusión ontológica del individuo biológico en la generalidad se va generando el cuerpo propio del Espíritu como un progresivo despliegue "lógico" al que corresponde una deducción de las facultades: la sensación, la intuición, la imaginación, el recuerdo, el sentimiento, el signo, el lenguaje y, sólo después de la memoria ("Gedächtnis») - mecánica y externa a diferencia del recuerdo ("Erinnerung»)- , surge primero el entendimiento abstracto y luego la razón, meramente individual hasta que el despliegue de la voluntad le da su dimensión social y política. El esquema tiene una interesante tradición ${ }^{4}$; pero me voy

3 Alguno de estos estudios se halla recogido en el importante trabajo de Gabriel AMENGUAL, Estudios sobre la "Filosofia del Derecho" de Hegel. Madrid: Centro de Estudios Constitucionales, 1989.

4 Vid. Filosofia real pág. 319 (ad 153/5), así como mi Comentario a la Filosofla del Espiritu de Hegel (op. cit., pág. $34^{18}$ ). 
a detener en un rasgo significativo: en la deducción el lenguaje es anterior al entendimiento y éste surge de él mediante el trabajo de una memoria que es repetición mecánica ; no procede expresivamente de contenidos, sino que constituye la suplantación heterogénea de éstos por un yo sin subjetividad, pura fuerza productiva que se da ser externo. Bastaría - no es poca manipulación- con desvincular ese "yo" del supuesto escolástico y especulativo que lo informa en Hegel, para encontrar a través de Hobbes el 'factum nudum' anterior a la razón y al sentido, que los constituye destituyéndolos de su valor de fundamento. El lenguaje no es expresivo ${ }^{5}$.

Hasta aquí un primer resumen de lo que Hegel va a pensar a partir de 1805/06. Si buscamos cómo lo formula en la Enciclopedia, nos encontramos con un contenido semejante en un contexto algo cambiado. La Enciclopedia es un tratado burocrático de "las ciencias filosóficas" en el sentido de que responde en cierto modo al esquema wolffiano, convertido en oficial. A la deducción de las facultades de 1805/06 se le añade así una "Antropología" empírica de corte escolástico y una "Fenomenología», que en las clases de 1805/06 sólo se insinuaba esporádica y precariamente. También la articulación Espíritu subjetivo - Espíritu objetivo - Espíritu absoluto de la Enciclopedia es más doctrinal que la anterior en concepto del Espíritu - Espíritu real - Constitución (arte, religión y ciencia como apartado final de lo político).

Pues bien, el \# 458, nota dice del signo:

«El signo es una cierta intuición inmediata que representa un contenido enteramente otro que el que tiene de por sí; es la pirámide, en la cual se ha depuesto y guarda un alma que le es ajena".

5 Filosofla real, 156-160 sobre el lenguaje. Los fragmentos conservados de las clases jeneses de 1803/04 encierran un pasaje mucho más largo sobre el lenguaje (HGW6. 280-298), con una embrollada especulación de aire schellingiano. Jürgen HABERMAS (Arbeit und Interaktion. Bemerkungen zu Hegels Jenenser «Philosophie des Geistes». En: (mismo), Technik und Wissenschaft als “Ideologio». Frankfurt/M.: Suhrkamp, 1968, págs. 9-47) se refirió a este pasaje en conjunción algo abusiva con el curso de 1805/1806, también porque enfocó este último desde la exposición del lenguaje en el contexto especulativo más desarrollado del trabajo y la familia (cf. Filosofia real 174, 186-190, 200). El texto condensado de 1805/06 repite en parte ese pasaje con un rigor deductivo hasta entonces inédito en Hegel, pues carece de la artística artificiosidad constructiva del texto anterior. A la vez que se reduce el aliento pótico de la especulación, se pierde asimismo la riqueza de matices y elementos reales, de los que soblo algunos encuentran cabida en el texto posterior. Independientemente de estas diferencias sistemática y de impostación, el texto anterior comparte la comprensión no expresiva del lenguaje, v. g.: «el nombre es de por sí, estable, sin necesidad de la cosa ni del sujeto" (pág. 288). 
Y hacia el final del apéndice al parágrafo anterior:

"Hay que proclamar la grandeza del signo [ ...., pues] ha acabado con el contenido de la intuición y ha animado el material de los sentidos con un significado que les es ajenon.

La "lógica" de estas afirmaciones la hallamos comprimida al comienzo "lógico" de la Enciclopedia (\# 20). Si la Filosofía del Espíritu de 1805/06 se abría con el yo abstracto, pura producción previa a toda subjetividad real, también en el comienzo de la Lógica conceptualmente "yo" designa la máxima individuación que es a la vez máxima replicabilidad:

"Lo que meramente miento es mío, me pertenece en cuanto soy este individuo particular. Ahora bien, si el lenguaje sólo expresa ${ }^{6}$ lo universal, resulta que no puedo decir lo que meramente miento.... Si digo «lo singulan", "este singular", "aquí", "ahora", todo eso son generalidades.... Igualmente, cuando digo "yo", quiero decirme a mí en cuanto soy éste que excluye a todos los demás; pero lo que digo, "yo», es precisamente cualquiera, cualquier yo en cuanto excluye a todos los otros».

El hiato del lenguaje se corresponde, por tanto con el hiato fundacional de la Lógica, como abría asimismo la Fenomenología del Espíritu (capítulo 1. ${ }^{\circ}$ ). Y tal vez concluyamos explorando qué pueda haber de eso. Por de pronto en el inmediato contexto enciclopédico la voz en off del oráculo se quiebra en un giro indignado contra dos villanos asociados que tontean delante del Espíritu absoluto; su nombre en realidad es legión, pero se los puede resumir como romanticismo y escepticismo, ambos caracterizados por una supuesta inmediatez al sentido:

«aunque lo ordinario sea tener lo inefable por lo superior, esta opinión, tan cultivada por la banalidad, carece de todo fundamento. Lo inefable no es de verdad sino lo turbio, en fermentación, y sólo si es capaz de acceder a la palabra, cobra claridad». (\# 462, apéndice.)

La larga nota original al \# 20 prosigue:

6 La Enciclopedia muestra aquí un uso exotérico del término "expresar", que casa mal con la teoría del signo en la Psicología hegeliana. Cf.infra, pág. 15. 
"Y lo inefable, sea sentimiento o sensación, no es lo más excelente ni lo más verdadero, sino lo menos significativo y verdadero".

Y la nota al \# 447 remacha:

"Es un prejuicio común que en el sentimiento hay más que en el pensamiento; y así se dictamina sobre todo cuando se trata de los sentimientos morales y religiosos. . . Pero la forma de la identidad singular que tiene el Espíritu en el sentimiento es la más baja y la peor, pues, lejos de ser el Espíritu en ella libertad y generalidad infinita, su riqueza y contenido intrínseco son algo contingente, subjetivo, particularm.

Como sigue la misma nota, "no hay más sensibilidad cultivada, verdadera que la de un espíritu formado a base de la conciencia de distinciones precisas, relaciones esenciales, determinaciones verdaderas, etc. ; y es esta forma la que justifica la incorporación de ese material en su sentimiento".

Ya se ve por qué el romanticismo sigue siendo aludido también en su compañero de viaje, el escepticismo. La nota al \# 445 considera propia de un talante abstracto y disperso - por cierto características del signo antes de ser sometido al trabajo de la memoria (\# 460, Filosofia real ps. 157 s.) — «la gran cuestión de los tiempos modernos, a saber, la de si es posible el conocimiento verdadero, es decir, el conocimiento de la verdad". Pero el apéndice al \# 441, también al comienzo de la Psicología, quizá por no proceder del corpus publicable, ataca ya furiosamente "la moderna desesperación por no poder supuestamente conocer la verdad", "suprema blasfemia" que desde luego "es absolutamente ajena tanto a la filosofía especulativa como a la auténtica religiosidad». "Si supieran lo que dicen, merecerían ser privados de la verdad".

La sobrecarga afectiva de este rechazo no me parece banal y merece seguramente cierta atención. Y es que alrededor del tema del lenguaje Hegel se ha planteado el tema de su propia vida junto con el de su tiempo. Precisamente esta conjunción fue la clásica reivindicación política de la burguesía frente a la aristocracia : que también su vida personal pudiera tener importancia política ; y que no la tuviera sólo la de los aristócratas, personalizando en forma de despotismo, intrigas y cabildeos - de ahí el polémico título de Schiller Intriga y amor ("Kabale und Liebe") - la prepotencia de sus cuerpos y su abuso de los cuerpos «inferiores». De esa conjunción personal/epocal deriva su energía una filosofía como la hegeliana. Incluso en su momento más "romántico», Hegel 
tiene tematizada la ruptura que va a centrar su posterior evolución especulativa ; comentando el pasaje del Evangelio según San Juan $(6,56)$ «el que come mi carne y bebe mi sangre en mí permanece y yo en él», un manuscrito de 1799 integrado en "El espíritu del cristianismo y su destino» ${ }^{7}$ dice así:

«el amor del cual se ha hecho algo objetivo, esta subjetividad que se ha transformado en una cosa, retorna otra vez a su naturaleza, se hace otra vez subjetivo en el acto de comer. Este retorno se podría comparar tal vez en este aspecto con el pensamiento que se transforma en una cosa en la palabra escrita ${ }^{8}$ y que, a partir de algo muerto, de un objeto, por el acto de leer recupera su subjetividad. El símil tendría mayor precisión, si la palabra escrita se disolviera en la lectura.... Si los amantes ofrecen un sacrificio ante el altar de la diosa del amor, y si la efusión de sus sentires en forma de súplicas enciende sus sentimientos hasta el máximo ardor, entonces la diosa misma ha entrado en sus corazones; su imagen de piedra, sin embargo, permanece ahí frente a ellos. En el convite del amor, en cambio, lo corpóreo se desvanece y sólo queda el sentimiento vivo".

Sin embargo, [.......] lo que impidió que esta acción llegara a ser religiosa fue precisamente el hecho de que el amor se hace visible en algo, se vincula a algo que debe ser destruido. El pan debe ser comido y el vino debe ser bebido ; por eso no pueden ser divinos.... ${ }^{9}$ se pretende que en el acto simbólico el comer y el beber se confundan con el sentimiento de la unión en el espíritu de Jesús. Pero la cosa y la sensación, el espíritu y la realidad, no se mezclan; la fantasía no los puede unir nunca dentro de algo bello.... Luego de la cena de los discípulos se suscitó una aflicción por la inminente pérdida de su maestro; después de un acto religioso genuino, en cambio, el alma entera queda satisfecha.

7 G. W. F. HEGEL, "Der Geist des Christentums". Schriften 1796-1800. Mit bislang unveröffentlichten Texten. Ed. W. Hamacher. Frankfurt: Ullstein, 1978, pp. 466 ss.: G. W. F. HEGEL, Escritos de juventud. Ed. J. M." Ripalda. Madrid: FCE, 1978, págs. 340-343.

8 Como ya queda indicado, en la sistemática posterior de la Filosofia real la palabra constituye la posibilidad, no la expresión, del pensamiento; éste se genera a partir de ella. En «El Espíritu del Cristianismo" tal concepción sólo se insinúa. La conjunción schilleriana de razón y sensibilidad guía la concepción del lenguaje.

9 También desde el enfoque fenomenológico Hegel seguirá insistiendo en que sin exterioridad distinta el Espíritu se halla a un nivel inferior de explicación; así la alusión al consumo del pan y el vino en los misterios eleusinos y a la relación del animal con su alimento (GW9. 69: Fenomenologta 69). 
Y entre los cristianos actuales surge, después de la comunión, un recogimiento sin animación, o bien con una animación melancólica; porque la tensión unilateral de la sensación estaba separada del entendimiento, unilateral también, y la veneración era incompleta. Se había prometido lo divino y se ha deshecho en la boca.

Las resonancias de este pasaje, surgido en el momento histórico del primer Romanticismo, son excesivas para un comentario siquiera sumario. Baste recordar que en Novalis se encuentra una tópica semejante, que Freud ha vuelto sobre ella y que Jacques Derrida en Glas (1984) ha dado un tratamiento tan extenso como fascinante de las implicaciones «sexuales» que atraviesan el sistema hegeliano y afloran recurrentemente en él, en concreto el incesto y la familia (temas a los que Marx y Engels, en la cercanía al Romanticismo, todavía fueron sensibles a su modo, como muestran sobre todo $L a$ ideologia alemana y La Sagrada Familia) ${ }^{10}$. Aquí sólo procede notar la importancia que tiene una problemática epocal y personal como lugar de la posterior especulación hegeliana. La pérdida del simbolismo divino del banquete sagrado es el motivo de una de las páginas más bellas de la Fenomenología del Espíritu ${ }^{11}$; otro motivo religioso tomado de la restauración de Grecia en la Ilustración tardía es la pérdida de aura del bosquecillo sagrado, reducido utilitaristamente a mera leña. Ambos temas pertenecen a la primera tópica que Hegel recogió de su ámbito cultural junto con el rechazo radical a la invocación de un supuesto estado de naturaleza, la nostalgia de un genuino imaginario político perdido y, en inmediata cercanía a nuestro tema, la equiparación entre lengua y dinero) ${ }^{12}$.

Si esta temática va a difuminarse relativamente quedando más bien como una resurgencia, cita, que yo compararía con un vulcanismo residual, el planteamiento teórico de fondo en el que Hegel la condensa, más bien va a afinarse que a ser sustituido ${ }^{13}$. En el pasaje comentado ese repensamiento pasa por

10 Cf. W. HAMACHER, op. cit., págs. 111-163.

11 HGW 9. 402: Fenomenologia 435 s. En La nación dividida. Ratces de un pensador burgués: G. W. F. Hegeh Madrid: FCE, 1978, pág. 239 s. cito una serie de pasajes sobre la conversión de la hostia en un pedazo de harina.

12 He estudiado esta tópica con cierto detenimiento en op. cit., págs. 60, 78-98, 164 ss., 201, 222-240.

13 Filosóficamente hay que tener en cuenta desde luego la importancia que cobra el esquematismo - un elemento mecánico, por así decirlo- en el intento kantiano de mediar razón y sensibilidad y la hipótesis mediadora de la 3.2 Crítica entre teoría y práctica, razón y sensibilidad. Pero de importancia más inmediata para Hegel son la reelaboración clásica que hace 
una teoría histórica del signo: el equilibrio clásico griego está amenazado inmanentemente por la inevitable externalidad de la estatua sagrada, mero signo del sentimiento de los amantes. La evanescente conversión del signo en símbolo que tiene lugar en el banquete sagrado, da paso a la religión de la interioridad, superior en la escala del Espíritu, pero a costa de perder realidad. Según el \# 458 de la Enciclopedia, completado con el apéndice al \# 457, en el símbolo se da una afinidad empírica entre signo y significado que corresponde a la fantasía, mientras que el signo procede sin necesidad de anclajes imaginarios por la pura fuerza de poner nombre en que se constituye la inteligencia; en su forma superior inaccesible al arte, como voz evanescente, guarda una afinidad con la religión del banquete eucarístico. Por eso también según la Estética hegeliana la literatura es el arte más noble y alto ontológicamente.

III.

Al final de las clases berlinesas sobre Filosofía de la religión recurre el banquete eucarístico como "centro de la doctrina cristiana", a partir del cual se explican las diferencias entre catolicismo, luteranismo y calvinismo ${ }^{14}$. En la eucaristía el catolicismo concibe

"a Dios como una cosa, al modo de una cosa empírica, y es consumido asimismo empíricamente.... De este modo surge la esclavitud de pensa-

Schiller de Kant y la pretensión de Schelling de convertir el arte en la culminación de la filosofía, en la que quedan superadas todas las divisiones. Esta pretensión schellingiana la especulación hegeliana la termina trasladando a la filosofía; así se explica la desmesurada pretensión del proyecto racional hegeliano. Por otra parte $\mathrm{Hegel}$ recibe con crecientes reservas el modo en que la teoría estética de Schiller trata de lograr una reconciliación entre razón y sensibilidad, privacidad y política mediante recurso a la Grecia clásica. En las condiciones modernas esa Grecia es incapaz de animar una solución pública, sino sólo soluciones privadas; lo único de que es capaz esa referencia a un arte modélico, "clásico", es de servir como elemento de formación - un aspecto en el que insistirá el Hegel educador de Nürenberg - y reflexión para la posición superior constituida por la filosoffa. Cf. Annemarie GeTHMANN-SIEFERT, Die Funktion der Kunst in der Geschichte. Bonn: Bouvier (=Hegel-Studien, Beih. 25), 1984.

14 Sigo la presentación del texto en $H W 17.328$ s., más manejable para una explicación. R. FERRARA sigue en su traducción (y edición, pues ha colaborado en la del Hegel-Archiv: Vorlesungen über die Philosophie der Religion. Teil 3. Die Vollendete Religion. Ed. W. Jaeschke. Hamburg: Meiner, 1984), una presentación critica: Lecciones de filosofia de la religión, Madrid: Alianza, 1985; el pasaje citado se halla en el tomo 3, págs. $245 \mathrm{~s}$. 
miento y obra ; este externalismo atraviesa todas las otras características, toda vez que lo verdadero se representa como algo fijo y externo. Y una vez que se da fuera del sujeto, puede caer en poder de otros; la Iglesia lo posee junto con todos los medios de salvación. En este sentido el sujeto es por completo pasivo, receptor, ignaro de lo que es verdadero, recto y bueno, sino que tiene que aceptarlo de otros».

Aquí la fusión del signo con su contenido - fusión a la que no sería ajena la ocasional invocación romántica del catolicismo medieval— produce la esclavitud de la letra, que a su vez se convierte en objeto apropiable de dominación (bastaría con poner aquí el término «democracia», para hacerlo intuitivo). En cambio según el luteranismo

«la presencia sensible no es nada de por sí y tampoco la consagración convierte la hostia en objeto de veneración, sino que el objeto se da exclusivamente en la fe; y del mismo modo la unión con Dios y la consciencia de esta unión del sujeto con Dios se da al consumir y aniquilar lo sensible. Es así como ha surgido la gran conciencia de que, aparte de ser comida y creida, la hostia es una cosa vulgar, sensible : lo que ocurre tiene su verdad exclusivamente en el espíritu del sujeton.

Aquíllama la atención el paralelismo entre el entusiasmo por "la gran conciencia» y la declaración del "signo como algo grandioso" en el apéndice al \# 457 de la Enciclopedia (cf. \# 458, nota). Hegel declara así su teoría del signo como genuinamente luterana y el luteranismo como la religión más cercana al Espíritu absoluto. En cambio el calvinismo sostiene que

"Dios sólo está presente en su representación, en el recuerdo, y por tanto sólo en cuanto tiene esta presencia inmediata, subjetiva. Tal es la idea que se hace el calvinismo, un recuerdo intenso, pero inerte [geistlos] del pasado, sin presencia divina, sin verdadero contenido espiritual. Aqul lo divino, la verdad se ha degradado en la prosa de la ilustración y del mero entendimiento como una relación meramente moral".

El calvinismo se instalaría, por consiguiente, en la percepción del bosque como leña, del mundo desangelado que constituyó la sensibilidad del joven Hegel. El sería en nuestros términos el representante del capitalismo ascendente (y Max Weber viene en su teorización de La ética protestante y el espiritu del capitalismo evidentemente tras Hegel y Marx). Pero es aquí donde la teoría 
hegeliana del signo se revela refractaria a su trasposición actual, pese a que a la vez siga sirviendo de referencia para una sensibilidad estética, cultural y política timorata, cuando no hipócrita. Según Hegel el signo rompe la presencia; pero no la excluye. Obliga a abandonar tanto la inmediatez obscurantista del catolicismo como el pragmatismo, desangelado o rigorista, del calvinismo; pero les impone la tarea de encontrar el sentido - Espíritu - en la materialidad a que se atienen, mediante una compleja operación especulativa. Dicho en los términos del apéndice al \# 462 de la Enciclopedia:

"cuanto más me familiarizo con el significado de la palabra, cuanto, por consiguiente, más se funde éste con mi interioridad, tanto más puede desaparecer su objetualidad y con ella la posible concreción [Bestimmtheit] del significado; y tanto más, por consiguiente, puede convertirse la memoria de ella, junto con la palabra, en algo que ha perdido el Espíritum.

Pero este "Espíritu" que realiza su 'kénosis', su cosificación más inerte en la palabra, sólo gracias a eso puede luego generarse en un proceso que, por ser reflexivo, puede ser calificado de interiorización. Según Paul de Man ${ }^{15}$, la ideología hegeliana del símbolo "nos resulta muy familiar en los lugares comunes de nuestro propio discurso histórico sobre la literatura. Domina, por ejemplo, la discusión del romanticismo en su relación con sus antecedentes neoclásicos, así como con su herencia en la modernidad. Determina las polaridades que forman los juicios de valor implicados en estas discusiones, oposiciones familiares como por ejemplo la que se da entre la naturaleza y el arte, lo orgánico y lo mecánico, lo pastoral y lo épico, el símbolo y la alegoría.... La metáfora dominante que organiza todo este sistema es la de interiorización, la comprensión de la belleza estética como una manifestación externa de un contenido ideal que es, él mismo, una experiencia interiorizada, la emoción recuperada de una percepción pasadan. (100: 103).

15 Me refiero a dos conferencias de 1980 y 1983 respectivamente, «Sign and Symbol in Hegel's Aesthetico y "Hegel on the Sublime", junto con la "Reply to Raymond Geuss" (1983), relativa a objeciones contra la primera conferencia. Los tres textos han sido incluidos en: Paul de Man, Aesthetic Ideology. Ed. with an Intr. by A. Warminski. Minneapolis/London: University of Minnesota, 1996. Hay traducción castellana de M. ASENSI y M. RicharT: Paul de Man, La ideología estética. Madrid: Cátedra, 1998. A continuación citaré en éste y otros casos análogos con dos cifras, la primera correspondiente a la edición inglesa, la segunda a la traducción castellana. Mis reservas con algunas apreciaciones de Paul de Man no afectan a la perspectiva teórica de su argumentación, que me parece ineludible. 
A este respecto procede comenzar matizando que la Enciclopedia y las clases berlinesas de Hegel, como elaboración filosófica de la realidad, son en parte un compendio de los conocimientos y actitudes de su entorno, a los que Hegel, en vez de rechazar, asigna un lugar especulativo. A veces la asignación de lugar inferior a un tópico es precisamente un recurso polémico. Tal es el caso de la degradación de la intuición frente a Schelling, o la preeminencia del signo sobre el símbolo, cuya definición kantiana en el \# 59 de la 3. ${ }^{a}$ Crítica Hegel supone constantemente, pero sin aceptar por ello la preeminencia del símbolo. El catolicismo, vigorosamente criticado, ocupa sin embargo un lugar eminente cerca del Espíritu absoluto; lo mismo que la Estética, pese a estar limitada especulativamente para Hegel por su carácter intuitivo y la tradicionalidad de ciertas ideas suyas, ha sido objeto de un tratamiento voluminoso y repetido en Berlín. No se puede olvidar que la teoría hegeliana del símbolo pretendía intervenir en una viva discusión de su época; el arte según los románticos era revelación sensible (del Absoluto según Schelling); lo que hace Hegel rebajando el lugar especulativo del símbolo frente al signo, es relativizar la inmediatez romántica tal como él la ve ${ }^{16}$. Una tarea fundamental del historiador de la filosoffa es, por tanto, dar su relieve a los puntos sensibles de esa masa, que pueden estar enterrados y desfigurados en su propio magma. Así la teoría del signo y el símbolo se articula a partir de puntos sensibles rastreables, como queda expuesto, desde la juventud de Hegel, mientras que en la Estética les incumbe, casi diría: les cae encima, la tarea de organizar una parte del sistema en la lejanía que impone un empeño enciclopédico. Los pasajes alrededor de esa teoría encierran, pues, valores diversos; y los textos no son homogéneos ni siquiera en ellos mismos.

Dicho esto, lo que más me interesa del pasaje demaniano es el tema de la interiorización que cierra su cita. La alusión a la belleza hegeliana como "experiencia interiorizada, la emoción recuperada de una percepción pasada» no casa del todo con la presentación del calvinismo que acabamos de ver. Para Hegel la inmediatez del recuerdo desemboca en la banalidad, y ésta fue una crítica fundamental suya al Romanticismo. De todos modos el tema no puede ser despachado rápidamente. Como bien sabe y dice de Man, Hegel al hablar

16 Discutible me parece de todos modos la afirmación de Yolanda EsPIÑA ("Kunst als Grenze: Die Musik bei Hegel». En: Jabrbuch für Hegelforschung, 3 (1997), pg. 106), bajo referencia a Gadamer, de que Hegel libera así el arte de tareas especulativas excesivas; siendo esto verdad, lo es asimismo que también lo ata a una tarea especulativa subordinada. 
del recuerdo ( Erinnerung») se atiene a su sentido etimológico (Er-innerung: interiorización activa ${ }^{17}$ ) como apropiación de la primera operación del Espíritu subjetivo, la intuición (Enciclopedia \# 452 ss.). El recuerdo, al igual que la intuición, que constituye, por así decirlo, su materia prima, es anterior genéticamente al entendimiento $\mathrm{y}$, por consiguiente, pertenece a los nombres que Hegel ha degradado a contracorriente del Romanticismo. En cambio la memoria ("Gedächtnis») adopta el sentido, también etimológico, de pensamiento cosificado o de suyo (Ge-dächtnis: de "denken", pensamiento, mientras que el prefijo "ge» insinúa el matiz de resultante o pasividad) y consiste en la repetición mecánica de los nombres hasta condensarlos en conceptos. El nombre y la memoria son superiores a la intuición y el recuerdo, luego mal podrá ser la interiorización, significado nuclear del recuerdo, la clave de la filosofía hegeliana ${ }^{18}$. Por eso en las clases berlinesas de $1827 / 1828$ sobre Filosofia del Espíritu (Vorlesungen, 13. 220) dice:

«Si la memoria es la más maravillosa de las fuerzas, ello se debe a que la inteligencia, esta interioridad, es esta completa externalidad".

Ciertamente la reflexividad del proceso especulativo insinúa al menos una cierta interiorización como característica del proceso del Espíritu. Pero esta reflexividad no es subjetiva, sino del concepto y en este sentido se ha desubjetivizado; la misma Fenomenología del Espiritu consiste en un largo proceso de dessubjetivización (aunque no simplemente desubjetivación, pues constituye «lógicamente» el sujeto). No es la inmersión en el tiempo interno lo que

17 Cf. las notas terminológicas 765 y 767 en la traducción de Valls Plana.

18 En un pasaje la interpretación en que se apoya de Man me parece que se aleja notablemente del texto de Hegel (los \#\# 459-463 de la Enciclopedia). En la pg. 102: 147 dice: "puesto que la síntesis de la memoria es la única actividad del intelecto que tiene lugar como manifestación sensible de una idea, la memoria es una verdad de la que lo estético es la traducción, defensiva, ideológica y censurada». Dada la relativa prolijidad aquí de la Enciclopedia, puede servir mejor de guía la clara y concisa exposición del mismo contenido en la Filosofia real (págs. 155-160). La sintesis de la memoria es "fuerza libre" que "se atiene a si como esta fuerza libre» (159/28 s.), no manifestación de una idea previa. Sólo la sintesis del recuerdo se basa en ideas previas; pero "idea" tiene entonces el sentido lockeano de la "palabra inglesa, ya que allí todavía se sigue llamando idea v. g. a la mera imagen de un perrow (155/7 ss., cf. 155/9-32). Por consiguiente lo estético no traduce la memoria; al contrario, la memoria es "necesidad vacía" (158/45 s.) y tomarla por base de la Estética desequilibrarla toda concepción del arte que buscara apoyo en Hegel; veremos cómo la interpretación maquínica de la inteligencia por Derrida enlaza con este Hegel. 
domina, aunque, como categoría, el tiempo sea superior ontológicamente al espacio; por eso al comienzo de la Filosofía del Espíritu de 1805/1806, al que corresponden las categorías psicológicas de que estamos hablando, el Espíritu "primero.... es como el animal tiempo que es para sí"; y Hegel ha anadido posteriormente: "a la vez que libertad frente al tiempo" (Filosofia real, $153 / 20 \mathrm{ss}.)^{19}$. La dinámica especulativa interioriza en el sentido de que como se veía en el \# 20 de la Enciclopedia - va acercando el yo nombre al yo aludido o el yo dicho al yo mentado; el reino de los signos cobra en ese acercamiento una cierta capacidad simbólica real, aunque inestable, pues está abocado a través de la comunidad religiosa a su definitiva transparencia al concepto, sin cuya virtualidad nunca habría sido. De hecho la estación terminal que es el Espíritu absoluto, no fagocita el trayecto, sino que le da sentido. Cualquier estación de ese trayecto dispone de un derecho a subsistir determinado en el tiempo y el espacio; el Espíritu hace justicia - y por tanto a la vez "ajusticia» - a todas. Ello conlleva una evidente rigidez especulativa; pero también la capacidad de admitir y explotar enciclopédicamente saberes de gran amplitud.

Cuando de Man abría su ensayo de 1980 «Signo y símbolo en la Estética de Hegel» con la constatación, en el fondo hegeliana, de que el disfrute inmediato de la literatura y la tarea de la crítica más bien se estorban recíprocamente, estaba tomando partido contra la absolutización de la crítica literaria frente a la literatura misma y seguramente indicando también la imposibilidad de esa critica literaria en el sentido "científico" del estructuralismo o del New Criticism. Pero, también con Hegel, ponía asimismo en la picota la inmediatez de la experiencia estética romántica -inmediatez, por cierto, de la que hay ejemplos impactantes en la postmodernidad-. Y, más allá de Hegel y contra él, de Man se oponía a asignar un sentido especulativo al arte, como se había seguido haciendo en la crítica literaria de los Estados Unidos o en la hermenéutica europea en formas sólo más desvaídas teóricamente, más vergonzantes que la hegeliana. Seguramente una limitación de los textos citados de Paul de Man tiene que ver con el hecho de que pretenden una liberación del nombre de Hegel - no tanto de los textos que nos han llegado bajo esa firma- ineludible en el contexto en que fueron escritos.

19 Para el tema del tiempo en Hegel me parece excelente el reciente artículo de Yolanda ESPIÑA citado supra, nota 18. 
IV.

Afirmaciones semejantes a las de Paul de Man y sobre la misma sección de la Enciclopedia se encuentran una docena de años antes en una ponencia de Jacques Derrida que procede del contexto de un excepcional seminario hegeliano dirigido por Jean Hyppolite ${ }^{20}$ : "Notemos en primer lugar que la producción más creativa del signo se reduce aquí a una simple exteriorización, es decir: a una expresión, la transposición exterior de un contenido interior, con todo lo que puede acarrear este motivo tan clásico" (Marges, p. 90).

En este pasaje se percibe mejor que en las citas anteriores de Paul de Man la pendiente que puede llevar insensiblemente a un desplazamiento de los significados oblicuamente, por así decirlo, a la línea que sigue el texto hegeliano. A partir de los pasajes que han ido apareciendo aquí cabe decir, en efecto, que el signo se constituye a partir de un "contenido" interior; pero en todo caso éste será heterogéneo al signo, no expresable por él; o, mejor dicho, incluso cada vez menos expresable, pues en la autogénesis del Espíritu se pierde la presencia intuitiva, el "para-mi" de la "Erinnerung" (recuerdo), precisamente por una operación de "Erinnerung" (interiorización) ontológica. La libre producción del Espíritu no es un contenido más entre otros, superado en el signo ${ }^{21}$. Como formula la Filosofia real $(156 / 13-18,157 / 19$ s.):

"Hasta ahora el yo es interioridad inmediata; tiene que acceder también a la existencia, hacerse objeto, esa interioridad tiene que invertirse haciéndose externa: vuelta al ser. Esto es el lenguaje como la fuerza de poner nombre. La imaginación sólo da forma vacla, la designa, sienta la forma como algo interior; el lenguaje, en cambio, sienta algo que esm.

Sólo en el nombre llega a superarse propiamente la intuición, lo animal y tiempo y espacio.

20 Le puits et la pyramide. Introduction à la sémiologie de Hegeh Cito por su última publicación en Jacques DeRRIDA, Marges de la philosophie. Paris: Minuit, 1972, págs. 79-127. Trad.: Margenes de la filosofia. Madrid: Cátedra, 1988. 103-144.

21 Derrida mismo lo dice poco después (págs. 91 : 114), precedido de la siguiente conclusión: "Producción e intuición, el concepto de signo será por consiguiente el lugar en que se cruzan todos los rasgos contradictorios». Aquí procede seguramente advertir que producción e intuición no son magnitudes simétricas más que por un momento, pues la intuición es una forma defectiva y virtual de producción a punto de ser superada. 
Hegel ha añadido al margen: "el límite totalmente contraído en sí, aislado». Es decir, la "cerrada noche de fantasmagorías» (154/19) que es la intuición, mantiene en la materialidad del nombre ese carácter inmediato, idiosincrático, aún propio del animal (cf. 136/26-30); pero el nombre tiene la forma general del ser, que abre esa materialidad, aunque aún sea "sin contenido propio" (157/24). Por consiguiente el nombre se halla en la divisoria real del Espíritu con una interioridad que no acaba de despegar de lo animal, la de las imágenes, la fantasía - tan cara a Schiller-y el recuerdo, la de la existencia en el tiempo y el espacio, kantianamente preracionales.

En realidad las diferencias de la Filosofia real con el texto posterior se deben aquí a algo más que al modo enciclopédico y relativamente estático de tener en cuenta el planteamiento ilustrado/kantiano de la imaginación en Enciclopedia, \# $457^{22}$. Por de pronto en el apéndice al \# 456 el recuerdo es precisado como conjunción con una nueva intuición inmediata, posibilidad que la Filosofia real (155/17-22) parece considerar sólo marginalmente. La Filosofia real procede más linealmente, como la Fenomenología del Espiritu, por sucesiva reflexión o explicación del para-sí, mientras que la Enciclopedia establece un sistema de interrelaciones entre los elementos emergentes y los ya existentes. El discurso de la Filosofia real resulta más plausible como deducción progresiva de la razón, pues no trata de aplicar a su propia génesis la forma que sería más desarrollada; la Enciclopedia, en cambio, — que aquí hace intervenir constantemente nociones aún no deducidas como "razón», «inteligencia»— extrae su mayor plausibilidad de rebajar algo el perfil de la deducción especulativa, a la vez que acentúa las conexiones tópicas y materiales que la dan su carácter enciclopédico. Por último la Filosofia real, en su condensación, no trata de deducir tantas "facultades" como la Enciclopedia; así la fantasía, meramente insinuada como «síntesis» (155/28), recibe en la Enciclopedia un desarrollo externo, temático, lo que me hace sospechar en él un cierto carácter exotérico.

22 Cf.Theodor BODAMMER (Hegels Deutung der Sprache. Interpretationen zu Hegels Ausserungen uber die Sprache. Hamburg: Meiner, 1969. 31 ss., 47 ss.) ha hecho una detallada exposición de las diferencias sistemáticas entre la Filosofia real y la Enciclopedia en punto a teoría del lenguaje. De esta importante monografia es especialmente interesante para nuestro tema el «\# 3. Sprache als Zeichen (Die psychologische Betrachtungsweise)». Sólo hay que tener en cuenta que, tratándose de una tesis doctoral defendida en 1966, aún habla de Jenenser Realphilosophie I y II, que trata de ambas como si no las separaran importantes diferencias sistemáticas y que, por último, subsume prácticamente el curso de 1805/1806 bajo el de $1803 / 1804$. 
A esto me parece deberse la presentación que hace del signo el \# 458, paralelo al pasaje citado de la Filosofia real: la inteligencia, como realidad virtual, anticipa desde la primera línea la deducción de la razón abstracta, siete parágrafos después, lo que induce a Derrida (op. cit., ps. 96, 104) a encontrar aqué el "concepto" ${ }^{23}$; la exposición enciclopédica de contenidos en los \# 458 - 460 y la nueva ubicación de la lexicología en la Antropología deja sin lugar a la explicación del proceso «lógico" en los términos de «la fuerza de poner nombren 24; en el \# 459 se acentúa el papel de la voz y el tiempo; y sobre todo se da plausibilidad a la función del signo en términos de signo y significado, comunes ciertamente con el texto de 1805 (156/11 s.), pero que allí, como ya queda explicado, no sólo apenas aparecían, sino que aludían bajo el nombre de significado a la negatividad misma. Así Derrida (p. 94) puede decir, sin faltar al texto, que Hegel habla "evidentemente de una idealidad por oposición a la corporeidad del significante intuitivo. Esta idealidad es la de un significado.... Habiendo tratado en un comentario anterior a las Investigaciones Lógicas de interpretarlo como el contenido de un querer-decir, trataré de mostrar aquí que la misma interpretación procede con el texto hegeliano.... El contenido de este querer-decir, de este significado, recibe de Hegel el nombre y la dignidad de un alma (Seele). Alma depositada en cuerpo, desde luego, en el cuerpo del significante, en la carne sensible de la intuición El signo, unidad del cuerpo significante y de la idealidad significada, se convierte en una especie de encarnación. La oposición entre el alma y el cuerpo y, analógicamente, entre lo inteligible y lo sensible, condicionan, pues, la diferencia entre el significado y el significante, entre la intención significante (bedeuten) que es una actividad de animación, y el cuerpo inerte del significantem.

Mi interpretación de Hegel difiere aquí, aunque algo dubitativamente, de la de Derrida. La negatividad, la fuerza de poner nombre, es más - y menosque una actividad de animación, que una intención significante, al menos si nos atenemos alos textos hegelianos sobre la Psicología. Por otra parte la Antropologia de la Enciclopedia habla a menudo de "expresión" y "expresar", aunque no sea referido a contenidos específicos, sino a un alma genérica, que

23 Hegel mismo advierte hacia el comienzo de la larga nota del \# 459 que está anticipando. Ahí mismo alude a la exclusión del contenido lexicológico de la Filosofla real en esta exposición de la Psicología de la Enciclopedia.

24 Filosofia real 156/16. Sin embargo, según el curso de 1827/1828 (Vorlesungen, 13. $219 / 57$ s.), "la inteligencia es el poder de los signos". 
representa la lógica, no precisamente lo indicado por la terminología aristotélica. Esta exposición «antropológica» juega también un papel importante dentro del Espíritu Objetivo (el lenguaje del Derecho) y en la Estética ${ }^{25}$; y tanto la tópica a disposición de Hegel como su propia sensibilidad pueden haber reforzado su papel. Sin embargo el enfoque antropológico es de rango sistemático inferior al psicológico.

En apoyo de mi interpretación quiero aducir por último un dato que me parece significativo e incluso da también su plausibilidad a la interpretación derridiana. A Hegel le ha costado llegar a formular definitivamente la exterioridad no expresiva del lenguaje. Cierto que desde los primeros textos de Jena la analogía del éter con el lenguaje explica éste claramente en términos de no expresividad 26; su aura se encuentra en el límite de lo existente surcado de nada. Sin embargo todavía en las clases de 1803/1804 (HGW 6. 282-295) la palabra oscila entre externalidad y expresividad y se constituye políticamente en el inmediato contexto del trabajo (318 s.). Es en la Filosofia real de 1805/1806 donde la exposición del lenguaje encuentra su lugar propio en un momento inicial, puramente teórico y por consiguientepre-práctico, pero decisivo, porque su lógica se va a reproducir recurrentemente en el trabajo, la familia, el contrato, la voluntad general. Ello le da a la teoría del nombre toda su pregnancia, a la vez que rebaja tanto el pathos estético/político como la riqueza de concreciones en que se exponía; el planteamiento antes animado de Romanticismo se reduce y concentra en la deducción conceptual, los ámbitos antes englobados se disgregan analíticamente a lo largo de esa deducción, se aplaza la satisfacción especulativa en el trabajo del concepto. Pero me parece arriesgado partir sin más del supuesto de una evolución que va dejando atrás etapas; éstas en todo caso siguen avanzando con Hegel y no necesariamente en la forma estricta de la 'Aufhebung' que el maestro ha impuesto a sus intérpretes. Puede ser que la Estética berlinesa no pueda ser entendida del todo sin tener en cuenta que una cierta posibilidad de oscilación en la misma noción de "bella apariencia" — desbancada por el nombre - tiene hondas raíces en la sensibilidad hegeliana y que la Estética en Hegel es más que una doctrina una hipótesis inacabada y con flecos, que destifie algo sobre el resto del sistema ${ }^{27}$.

25 Cf. Theodor BODAMMER, Hegels Deutung der Sprache. Interpretationen zu Hegels Äu(erungen über die Sprache. Hamburg: Meiner, 1969. \# 6.

26 Cf. Filosofla reah págs. xxii s.

27 Vid. A. GETHMANN-SiefERT, op. cit., págs. 8, 181, 292 s., 359. 
En cualquier caso nada más lejos de mi intención que defender a Hegel de Derrida en una de esas que en el fondo suelen ser luchas soterradas entre antiguos nacionalismos culturales. Aunque Derrida en ese texto de hace ya 30 años recorriera penosamente el difícil terreno hegeliano, sin duda disponía de una buena brújula. De hecho termina con el Prólogo de 1807 en el punto en que le habría podido dejar, con el lenguaje, el primer silogismo de la Filosofía del Espíritu de la Filosofia real o la "mecánica» de la memoria en la Enciclopedia (\# 463): "el cálculo, la máquina, la escritura muda pertenecen al mismo sistema de equivalencia y su trabajo plantea el mismo problema: en el momento en que el sentido se pierde, en que el pensamiento se opone su otro, en que el Espíritu se ausenta de él mismo, ¡es seguro el rendimiento de la operación?.... ¿Qué sería un "negativo" sin posibilidad de superación?.... Muy simplemente una máquina, por ejemplo, y una máquina que funcionaría. Una máquina definida en su puro funcionamiento y no por su utilidad final, su sentido, su rendimiento, su trabajo.... lo que Hegel, intérprete eminente de toda la historia de la filosofía, no ha podido pensar nunca, es una máquina que funcionara" ${ }^{28}$. Solamente, que Derrida tal vez ya sabía esto antes de transitar el territorio hegeliano. Posiblemente era inevitable pasar por Hegel en el contexto del seminario de Hyppolite y de la filosofía francesa de entonces; Derrida se encontraba ahí y basta ${ }^{29}$. Su recorrido por Hegel seis años después, Glas, lo más impresionante que conozco sobre Hegel, es otra cosa; Derrida vuelve para hacer esta vez espeleología y parapente.

V.

Los textos citados de De Man y Derrida dejan la impresión como de una exploración, un rebote en el planeta Hegel. El modo en que sus preguntas inciden sobre el texto hegeliano acusa cierta dificultad de traducción a otro terreno. Y desde luego la teoría hegeliana del lenguaje, del signo y del símbolo se

28 Op. cit., págs. 125 s. A pesar de lo rotundo de esta afirmación la posición de Derrida frente a Hegel es desde siempre muy matizada. Cf. Gabriella BAPTIST, Hans-Christian LuCAS, "Wem schlägt die Stunde in Derridas "Glas"?". En: Hegel-Studien 23 (1988), págs. $156 \mathrm{s.}$

29 Más conocido es otro artículo de Derrida del mismo ano y publicado asimismo en Marges. ousia et grammè, note sur une note de Sein und Zeit, págs. 31-78: 68-102 de la traducción citada. Este artículo, interesante por la discusión a tres con Heidegger y Hegel, si ha suscitado una cierta atención polémica en la academia alemana. Cf. Filosofia real. 258. 
queda muy por debajo de las exigencias teóricas actuales, mucho más diferenciadas ${ }^{30}$. Pero siguen diciendo algo que no me parece que queda suficientemente explorado con el recurso a una tradición metafísica, en la que Hegel seguiría inmerso de pleno. Por lo menos, como Derrida indica al final de su ponencia, no le han bastado a Heidegger mismo, tan pródigo en ese recurso, para escapar a su propio dogmatismo. En cuanto a la "interiorización" hegeliana, el planteamiento especulativo de conjunto la sitúa en una tensa relación con su externalidad; la misma subjetualidad racional, lugar privilegiado del Espíritu, no puede agotarlo. El Absoluto es el sentido; pero nadie, ni individual ni colectivo ni estatal, dispone de él. Tampoco el lenguaje puede absorber la verdad. Cuando, al culminar la exposición, el sistema se contrae sobre sí mismo, no reina el lenguaje, sino más bien el silencio, o una oscilación entre ambos, en la que el lenguaje sólo interviene como tímida indicación, pues «la ley es la cesura» ${ }^{31}$.

Esta externalidad nos es hoy tan familiar que apenas podemos evitar que se nos imponga al volvernos a Hegel. Este no era aún el caso de Jean Hyppolite, cuando escribió Lógica y existencia ${ }^{32}$. Y Derrida, al comienzo de "El pozo y la pirámide», declara haberse referido implícita y constantemente a este libro, que desde luego le ha guiado en sus citas hegelianas. Pero, aparte del homenaje que se puede suponer en esta referencia a quien acababa entonces de fallecer, Hyppolite representa una culminación ${ }^{33}$, mientras que en el texto de Derrida asoma un surgimiento; y estas cesuras no las puede suturar una historia de las citas e influjos. Hyppolite es el último filósofo productivo/comentador de Hegel en una serie francesa algunos de cuyos hitos son Wahl, Koyré, Kojève. El interés dominante por la Fenomenología del Espiritu va evolucio-

30 Por de pronto la Filosofia real insiste en el sustantivo como elemento último del lenguaje, aunque también aquí caben matizaciones, puesto que eso vale sólo en un momento del sistema. Cf. F. LI VIGNI, op. cit., págs. 169 s. $^{42}, 178$ s. $^{52}$.

31 Jacques Derrida, Schibbolet. Pour Paul Celan. Paris: Seuil, 1984. 16.

32 Logique et existence. Essai sur la Logique de Hegel. Paris: PUF, 1953. Trad.de L.Medrano, Lógica y existencia. Barcelona: Herder, 1996. A continuación cito por las dos ediciones, unidas con dos puntos en este orden.

33 En el mismo comienzo de una obra casi sin otras referencias que los textos de Hegel, Hyppolite reconoce —en una cláusula de tipo semejante a la que abre «El pozo y la pirámidensu deuda con Kroner y Mure, es decir, con una forma de hacer historia de las ideas como historia de los sistemas, en la que el ciertamente introduce su propia sensibilidad a la circunstancia cultural en que vive. 
nando en Hyppolite hacia la Ciencia de la Lógica, la Estética, los escritos de Jena; y esta deriva poco aparatosa, característica de Lógica y existencia, va a facilitar uno de los nichos en que Derrida va pensando inicialmente a Hegel, Heidegger y Husserl juntos. Por lo demás la coyuntura Hegel centrada en la Fenomenología del Espiritu que había durado desde la crisis del veintinueve a las revueltas estudiantiles de los 60, acusaba ya signos de desgaste.

Lógica y existencia es una exposición del Saber absoluto como modelo especulativo de enorme potencia con el que es preciso confrontarse. En él habría encontrado el ansia integradora de Hegel una liberación contemplativa del tiempo y de la memoria, despreciando el recurso romántico al infinito a través de la intimidad espontánea. El Absoluto es la versión hegeliana del Fausto, en una extensión del Eros tan inmensa como disciplinada por el concepto. Un año antes de "El pozo y la pirámide» Derrida, comentando a otro lector del mismo libro de Hyppolite y viejo hegelita de la escuela de Kojève, Georges Bataille, había descrito la imposibilidad de este proyecto especulativo y su sustitución por otra economía especulativa, a cuyo borde Hegel se habría asomado para retirarse asustado ante el abismo irrecuperable del sin-sentido ${ }^{34}$. Y al tema del sentido se refería Hyppolite, cuando desde el mismo prólogo acometía el tema del lenguaje:

"¿Cómo puede decirse el ser en el hombre, de modo que el hombre se convierta por el lenguaje en conciencia universal del ser? Para tratar de responder a esta cuestión primordial es preciso exorcizar el fantasma del nosaber, como de un inefable, mostrar cómo el lenguaje humano se constituye como el ser-ahí del espíritu y el sentido del ser, y por último descartar por lo mismo la noción de un lenguaje propiamente técnico que no fuera a la vez sentido y lenguaje, sino cálculo extrínseco, manejo exterior de los signos» ${ }^{35}$.

Hyppolite se apoya en este caso en un texto exotérico sobre el lenguaje (al comienzo del prólogo a la 2. ${ }^{2}$ edición de la Ciencia de la Lógica), un pasaje, por cierto, en el que no figura el término «sentido", subrayado por la interpreta-

34 "De l'économie restreinte à l'économie générale. Un hegelianisme sans réserve». En: Jacques DERRDA, L'écriture et la difference. Paris: Seuil, 1967. 369-407. Trad. De P. Peñalver en La escritura y la diferencia. Barcelona: Anthropos, 1989, págs. 344-382.

35 P. 6: 12. Entre las primeras publicaciones de DERRIDA se encuentra precisamente un estudio sobre la concepción husserliana de la geometría, el largo estudio introductorio al Origen de la geometria de HUSSERL: Edmund Husserh L'origine de la géométrie. Paris: P.U.F., 1962. 
ción de Hyppolite. Es más, cuando Hyppolite cita el texto de la Filosofia real (ps. 156 s.) en que se expone la teoría hegeliana del lenguaje, se permite entre otras manipulaciones - seguramente justificadas para Hyppolite por su identificación con Hegel- «completar" el texto que presenta el nombre como «el ser del objeto", añadiendo a continuación dentro de la cita hegeliana como si perteneciera a ella: "el ser como sentido" (Hyppolite 39: 47). La interpolación es especialmente inoportuna, porque Hegel ha subrayado el término "ser», indicando que de lo que se trata es de la externalidad radical del nombre. Tanto en el inmediato comentario a ese pasaje como en el resto del capítulo $2 .^{\circ}$, "Sentido y sensible", en el que se encuentra - y en el que se inspiran las citas de Derrida -, Hyppolite insiste en el "sentido" y la "expresividad", lo que no es tan falso, de atenerse al conjunto del sistema hegeliano, pero borra el perfil específico del texto citado. La mezcla constante de citas de Hegel de distinta cronología y status textual indica por otra parte que Hyppolite supone desde la identidad del sistema una homogeneidad autorial/sistemática de los textos de Hegel, que él, Hyppolite, representa por identificación. Sin embargo de los tres significados de "sentido" - sentido corporal, significado y consistencia ontológica - los dos últimos se hallan para Hyppolite en una identificación que en Hegel es menos ingenua, pues al menos requiere una explanación sistémica sin precedente. Y era la imposibilidad de esa identificación la que inspiraba la interpretación de Hegel por Bataille, atenta a la cesura que introduce precisamente el intento de suturarla en el Absoluto.

Si la presentación que hacía Hyppolite del Absoluto ha podido incidir simplificadoramente en una interpretación de Hegel por Derrida, por ejemplo asociándolo con Husserl en una filosofía del sentido, sin embargo su conjunción con Bataille ha servido a Derrida para, tomando pie del juego, la risa, la locura, la poesía, el riesgo, activar la radical exterioridad en que se constituye el lenguaje y el sentido. No debe de ser casualidad que Hegel mismo haya advertido sobre el tema del lenguaje que es «uno de los puntos hasta ahora ignorados por completo y realmente de los más difíciles en la doctrina del Espíritu" ${ }^{36}$. Seguramente lo primero es darse cuenta de que Hegel no se lo ha hecho fácil y de que la misma seriedad especulativa con que Hyppolite trata de interpretarlo, le pone recurrentemente en dificultades. Seguramente es la elaborada percepción de la externalidad en que se constituyen la razón y el senti-

36 Enciclopedia, \# 464, nota. HyPPOLITE (35: 42 s.) se refiere también a este pasaje. 
do, la que ha permitido a Derrida (y a de Man) anticiparla intelectualmente como rasgo general de la cultura postmoderna, pese a que al menos Derrida encaja difícilmente en ella. La tecnologización de la memoria y la producción industrial de la imaginación, la constitución de la subjetividad como posición de mercado audiovisual y como atribución a segmentos de consumo sienta una situación a la que la "máquina" derridiana parece aludir genérica y cultamente. Y sin embargo la concepción expresiva del arte es hoy, a la vez, estética de masas (y me refiero a masas cultas estética y políticamente, no a las masas odiadas por Horkheimer y Adorno), como sigue siendo política de masas la democracia sustancialista y la ética normativa. Ello hace, por cierto, más fácil el cinismo. El stablishment político español -en este momento sobre todo el oposicional- está repleto de antiguos revolucionarios en olor de Tschaikowski, luchadores conmovidos por Serrat y demás miembros de las tribus progres que en ellas reencontraron - $\mathrm{y}$ a veces han perdido para su desolación - la inmediatez que Hegel dio por imposible ${ }^{37}$.

Por el contrario, según Hegel, incluso en el arte más elevado, el poético, que se expone en la palabra, los dramas de Schiller mostrarían que el ideal estético no puede garantizar su realización sino en selectos jardines de Epicuro; el artista siempre será un individuo idiosincrático, la forma artística inadecuada al Absoluto, fugaz y precaria, como toda expresividad. Desde la Filosofia real el arte y su capacidad expresiva se consideran incapaces de reintegrar la externalidad moderna. Si el arte puede aparentar legítimamente esa reintegración, es porque en él el Absoluto se presenta en forma intuitiva a la reflexión ${ }^{38}$. Pero precisamente el esquematismo "lógico" hegeliano encierra un descubrimiento "postromántico" que hoy en día sigue sin acabar de asimilarse. Tanto la precariedad especulativa del arte como sus tres grandes estadios históricos tienen que ver directamente con la teoría hegeliana del signo, según formula pregnantemente la Enciclopedia desde su 2.a edición (\# 556-563 de la 3. ${ }^{a}$ ed.). El

37 Incluso en Adorno, el más serio de los "progres", perdida la expectativa de una humanidad aceptable, se trata de afirmar expresivamente al individuo disconforme contra su mundo; de ahí su exigencia de una música expresiva en su misma externalidad formal. Sobre la compleja estética adorniana y sobre las tensiones no menos complejas que surcan la estética de masas cf. J.M. ${ }^{2}$ RIPALDA, De Angelis. Filosofta, mercado y postmodernidad. Madrid: Trotta, 1996, cap. 8, "Adorno y el Espíritu objetivo".

38 Sobre la intuición vid. Filosofia reah págs. 153-160; Enciclopedia, \#\# 446-460. El lugar definitivo del arte en el sistema hegeliano lo explana por primera vez la Filosofia real en las págs. $226 \mathrm{~s}$. 
arte simbólico se mantiene al nivel de una relación de cierta similaridad entre el signo y su significado; el arte clásico alcanza una fugaz identificación entre ambos ; pero sólo el arte romántico accede a la abstracción singular del signo y con ello culmina el arte a la vez que inicia su desbancamiento, lo mismo que la palabra deja atrás la intuición (Filosofia real, 157/19 s.).

Esta capacidad de reintegrar en una síntesis global la percepción de la disgregación y externalidad ineludibles nos fascina seguramente, porque reproduce nuestra situación incoherente, que comparte la misma intuición y análogos trucos reconstructivos, aunque sin necesidad de confrontarse con la tarea de justificarse con un sistema especulativo. Seguramente es al final de la segunda parte de la Estética, al exponer la disolución del arte romántico, cuando Hegel está en la máxima cercanía a fenómenos modernos/postmodernos, como son la arbitrariedad en el uso de formas, temas, materiales y motivos, incluidos - como Hegel nota expresamente- los más vulgares, porque se hallan en máxima exterioridad a una interioridad hipertrofiada. Hace tiempo que el mismo arte ve cuestionadas sus seguras fronteras y actúa en infinita diseminación ; a la vez productos que se pretenden específicamente artísticos, transmiten por eso mismo una impresión patética. Es como si en una inversión de la consgina del "fin del arte" todo se hiciera arte y por tanto nada lo fuera, aunque lo cuestionado sea en realidad la frontera misma que pretende definir el arte.... o la literatura, la filosofía, la que define por tanto - y esto es menos inofensivo - al crítico de arte, al historiador de la filosofía, etc. ${ }^{39}$.

Lo que Hegel no reconoce a esa exterioridad que hace inverosímil viejas clasificatorias, es la fuerza arrasadora para la subjetividad que hoy tiene valor de evidencia ineludible. Incluso dentro de su sistema podría haberlo hecho, como lo hizo con «la fuerza de poner nombre»; pero el signo, como él lo plantea, tiene una realidad demasiado inerte, dependiente del momento interior constitutivo ("la fuerza»). Cierto, conforme al curso de 1805/1806, el nombre es a la vez el signo y lo significado; su referente, si se quiere hablar así, no puede ser extraído fenomenológicamente, porque no es intencional ; también, así como el Espíritu es pura relacionalidad, el nombre, a diferencia de la arbitrariedad del signo, se constituye en lenguaje por el orden. Pero el factor expresivo, siempre presente, aunque marginal a la deducción, seguramente recobra

39 Cf. Gabriella BAPTIST, "Ancora un confronto tra poetare e pensare? Derrida e Celan tra Hegel, Hölderlin e Heidegger». En: Paradigmi, XV (1997), n. 43, pág. 126. 
fuerza - por más problemática que sea- en la Estética. Como corresponde al momento en que la nueva subjerividad burguesa, en el borde entre la revolución política e industrial y el Antiguo Régimen, condensa un nuevo mundo virtual, la percepción estética hegeliana -que es en el fondo la de su sistema especulativo- es fundamentalmente subjetiva, la del tiempo interno. Así lo muestra la adjetivación en el pasaje que cierra la exposición sobre el arte romántico, que hoy sería irrelevante en el mejor de los casos : profunda («tiefe Empfindung"), certero ("treffender Witz»), esclarecedora ("sinnreiche Reflexion"), inspirada ("geistvolle Bewegung der Phantasie") ${ }^{40}$. La interpretación derridiana de la «interiorización» hegeliana como intencionalidad puede ser que traslade a Hegel demasiado Husserl; pero marca una distancia ineludible, distancia que Derrida mismo ha ido recorriendo, a medida que la deconstrucción se iba perfilando como realidad teórica y ocupaba su lugar disconforme en la situación postmoderna.

Pero a su vez una filosofia así, en la percepción activa no sólo de su propia externalidad, sino de ella como oscilación sin lugar de referencia, acoge con extrema tensión la situación de una interioridad romántica, ahora desertizada, que ya no requiere ni siquiera la tensión expresionista o existencial ${ }^{41}$. Recordando a Paul de Man, y en concreto su artículo comentado antes ${ }^{42}$, Derrida percibe el recuerdo del amigo perdido como una serie inconexa de fragmentos dispersos, que a su vez son partes de nosotros en una memoria que excede nuestro espacio y tiempo internos (como por cierto ocurría en Hegel con 'Gedächtnis' y 'Erinnerung'), fuera de nosotros en nosotros, nosotros en ese fuera, en la materialidad de la palabra. Pero esta memoria es a la vez menos que el recuerdo singular, se contiene y condensa en él como si la parte fuera más que el todo y porque también -contra Hegel- lo es. La palabra es alegórica; designa, no expresa, su juego es el de la muerte, inscrita de antemano en la iterabilidad ilimitada del nombre propio más allá de la muerte de su detentador y de la multiplicidad de sus detentadores o - como ya quedaba indicado en la Enciclopedia (\# 20)— inscrita en la imposibilidad de decir un yo que lo sea realmente.

40 G. W. F. Hegel, Ästhetik. Ed. Fr. Bassenge. Berlin: Aufbau, ${ }^{3} 1976$. T. I, pág. 583: Lecciones de Estética. Trad. R. Gabás. Barcelona: Península, 1991. T. II, pág. 173.

41 Aquí me refiero concretamente a la posición de Paul de Man en "Heidegger y las exégesis de Hölderlin", en: Visión y ceguera. Ensayos sobre la retórica de la critica contemporánea. Universidad de Puerto Rico, 1991, págs. 277-301.

42 Jacques Derruda, Mémoires pour Paul de Man. Paris: Galilèe, 1988, págs. 54-65. 
La percepción del tiempo interno queda subordinada a esa anterioridad irrecuperable, material, por tenue que sea esa materia en que se constituye, desintegrado desde siempre de un sentido propio. Darse tiempo en los ritmos de esa materialidad pudiera ser un proyecto posible de la alta cultura en Derrida. Darse tiempo desde la materialidad del espacio podría ser otra posibilidad sugerida v. g. por las esculturas de Cristina Iglesias en el campus de la UNED de Senda del Rey, ellas también una operación de la alta cultura en el trabajo anticuado y artesanal del escultor. Políticamente el explícito sería Derrida, propugnando la dirección opuesta a la que hoy funciona en la democracia autoritaria; en vez de utilizar los principios para identificar con ellos el 'statu quo', ¿hacerles y hacer justicia caso a caso con y contra ellos? Sería otra versión del "reconocimiento" que, a diferencia de la "Anerkennung" hegeliana, no necesita recurrir al sentido universal y sin embargo no es in-sensata. 